\title{
Implicações da Assistência Humanizada no Atendimento Pré- Hospitalar: Revisão Integrativa
}

\author{
Fonsêca, Jéssica Ramalho da; Silva, Raymara Alves da; Ramos, Ana Raquel Xavier; Silva, \\ Liniker Scofild R. da; Correia, Nathália da Silva; Cordeiro, Eliana Lessa \\ Universidade de Pernambuco — jessica_ramalho1409@hotmail.com
}

Introdução: o número de ocorrências que necessitam de Atendimento Pré-Hospitalar - APH tem aumentado cada vez mais no Brasil. em Recife, no ano de 2011, o Serviço de Atendimento Móvel de Urgência - SAMU 192 teve uma média de 4,1 mil acionamentos/mês, o que representa uma média 49,2 mil atendimentos/ano. Já em 2013, o referido serviço foi solicitado 116.281 vezes, de acordo com dados apresentados pelo mesmo. no estado de Santa Catarina, dados revelam um aumento de 31 mil atendimentos em 2013, quando comparados a 2012. o momento em que há a necessidade do acionamento de algum serviço de urgência é sempre muito delicado. o desespero, nervosismo, medo e irritabilidade estão presentes tanto na vítima quanto nos familiares. e isto não se restringe apenas aos protagonistas do acontecimento; tais sentimentos envolvem, também, aqueles que presenciaram o episódio e curiosos que se dirigem ao local da ocorrência. Este fato é muito importante e pode influenciar na qualidade de atendimento à vítima, visto que o profissional deve lidar com todos estes personagens simultaneamente. Objetivos: Desenvolver conhecimento científico visando estimular a prática da assistência humanizada no Atendimento Pré-Hospitalar. Método: Trata-se de uma revisão de literatura referente à prática de atendimento humanizado no APH e suas implicações na qualidade da assistência prestada. para tanto, houve a revisão e análise de 05 (cinco) artigos, dos últimos 05 (cinco) anos, descritos na literatura científica brasileira, disponíveis na íntegra na base de dados do Scielo, além da análise de dados do SAMU de Recife/PE e Santa Catarina, disponíveis nos sites da Prefeitura do Recife, do SAMU de Santa Catarina e da imprensa local do Nordeste. Resultados: Diante dos estudos analisados, observouse que os itens agilidade, conflito, pré-hospitalar e nervosismo geram uma rede de tensão que abarca tanto os envolvidos na ocorrência, quanto os profissionais de saúde. nos casos em que o profissional atuou de maneira humanizada, as vítimas e os demais sujeitos se mostraram mais calmos e confiantes, o que facilitou bastante o atendimento. por esta questão, faz-se necessário atuar de maneira humanizada, visando acalmar os indivíduos envolvidos, reconhecer e valorizar sua singularidade e assim prestar uma assistência de qualidade. Conclusão: Frente a este estudo infere-se a necessidade de agir de acordo com as políticas de humanização no campo da saúde. É indispensável que os atores valorizem os sentimentos e crenças de todos aqueles que estão inseridos no contexto dos atendimentos, enxergando sua individualidade e considerando suas opiniões. Dessa forma, obtem-se êxito e a integridade do usuário é sempre garantida.

Fonsêca, Jéssica Ramalho da; Silva, Raymara Alves da; Ramos, Ana Raquel Xavier; Silva, Liniker Scofild R. da; Correia, Nathália da Silva; Cordeiro, Eliana Lessa. Implicações da Assistência Humanizada no Atendimento PréHospitalar: Revisão Integrativa. In: Anais do Congresso Internacional de Humanidades \& Humanização em Saúde [= Blucher Medical Proceedings, num.2, vol.1]. São Paulo: Editora Blucher, 2014. ISSN 2357-7282 DOI 10.5151/medpro-cihhs-10718 